\title{
The use of ICT and Social Networks for Learning in Technical Courses at IFSC
}

http://dx.doi.org/10.3991/ijes.v2i1.3679

C. T. Vianna, Instituto Federal de Santa Catarina, Gaspar, Brasil

G. M. Tenfen, Instituto Federal de Santa Catarina, Gaspar, Brasil

A. P. Cândido, Instituto Federal de Santa Catarina, Florianópolis, Brasil

Abstract - Since 90s new tools have emerged providing many facilities for learning; despite after almost two decades yet many educators resist against their use, either for convenience, lack of skills with the tools or because they do not believe in their effectiveness. This study presents an experience in use of various collaborative tools and information technology as moodle, wordpress, facebook, emulators, management applications, games and real projects, theater and film, drawing on supported by information technology environments. The results obtained at IFSC appear promising not only in technical learning, but in the formation of citizens.

Index Terms — social networks, information technology, learning, ubiquitous learning

\section{O uso das TIC e das Redes Sociais no aprendiza- do em cursos técnicos no IFSC}

\author{
VIANNA. Cleverson Tabajara ${ }^{1}$, TENFEN. Glaucia Marian ${ }^{1}$, CÂNDIDO. Antônio Pereira ${ }^{2}$ \\ ${ }^{1}$ IFSC/Gestão e Negócios, Gaspar, Brasil \\ 2 IFSC/Informática, Florianópolis, Brasil
}

\begin{abstract}
Resumo-A partir dos anos 90 novas ferramentas surgiram proporcionando muitas facilidades na aprendizagem; a despeito de decorridos quase duas décadas ainda muitos educadores resistem ao uso, seja por comodidade, falta de habilidade com as ferramentas ou porque não acreditam em sua eficácia. Este estudo apresenta a experiência no uso de diversos ferramentas colaborativas e de tecnologia da informação como moodle, wordpress, facebook, emuladores, aplicativos de gestão, jogos e projetos reais, teatros e filmes, valendo-se de ambientes suportados pela tecnologia da informação. Constatamos pelo que vivenciamos no campus Gaspar, do IFSC, que os resultados se mostram promissores não apenas no aprendizado técnico, mas na formação do cidadão, deixando de ser a sala de aula mais um instrumentos de organizações que poderemos por vezes, chamar de "opressoras".
\end{abstract}

Palavras-chave-redes sociais, tecnologia da informação, aprendizagem, educação ubíqua.

\section{INTRODUÇÃO}

A globalização é hoje motivo e causa de modificações no mundo e seus efeitos são sentidos em todas as áreas e mencionadas em uma enormidade de trabalhos científicos. Para Tapscott e Wiliams [1], é esta globalização que está a permitir a coexistência de empresas e indivíduos, todos criando (individualmente ou coletivamente); é uma nova forma de economia a qual chamam de economia colaborativa.

Neste documento, visamos apresentar a experiência no uso de ferramentas colaborativas e de tecnologias de informação e comunicação (TIC), como coadjuvantes no processo de aprendizagem. Após uma breve discussão do referencial teórico, traremos a experiência do uso do moodle, lousa digital, programas Enterprise Resource Planning (ERP) em demonstração e o uso das redes sociais, fatores considerados importantes e complementares à atuação do educador e dos alunos.

Trata-se aqui de, valendo-se do viés dos Cursos Técnicos, observar a atuação e resposta dos alunos aos diversos mecanismos utilizados, e destacando os benefícios alcançados em cada um, em termos de facilidade e utilidade, de resultados esperados e alcançados e, especialmente, de atenção e satisfação dos alunos, eliminando o aspecto de possível organização opressora.

Não nos deteremos aqui em aspectos pedagógicos, se estamos utilizando o Comportamento Cognitivo - Sócio Construtivista ou Conectivismo; trataremos de apresentar a vivência prática na aplicação destes modelos e que por muitas vezes se confundem em sua aplicação e que se utilizam quase sempre de forma rápida e alternada, aparentando uma simultaneidade de métodos (vide Quadro 1$)$.

Nossas turmas do Curso Técnico em Administração, do Câmpus Gaspar do Instituto Federal de Santa Catarina (IFSC), apresentam uma média de 24 alunos, embora as vagas ofertadas sejam 40 . Com a exigência dos estudos e avaliações e agravadas pelos compromissos familiares e responsabilidades sociais muitos alunos desistem pelo caminho e registramos, em média, uma defasagem de $40 \%$. Com a intensa atuação da área pedagógica, através da assistência estudantil, e da perseverança dos professores, o índice de evasão tem diminuído. Há que observar que em outros cursos o número de concluintes é próximo a $1 / 4(25 \%)$, mas estamos melhorando a cada dia.

Especificamente nos nossos cursos da área de Gestão e Negócios, durante o período vespertino, os alunos estão em geral na adolescência e quase todos são estudantes por profissão, tendo maior disponibilidade e compromisso com os estudos. No turno da noite, a procura é maior pelo curso e quase todos são adultos, trabalhando 40 horas semanais ou mais. A participação e interação dos alunos é 


\section{O USO DAS TIC E DAS REDES SOCIAIS NO APRENDIZADO EM CURSOS TÉCNICOS NO IFSC}

o fator fundamental para que se cultive não apenas o conhecimento científico e prático, mas a razão substantiva de sua evolução, "somente através da livre experiência da realidade e de sua precisa articulação é que a racionalidade substantiva poderá ser compreendida" [3].

Mesmo em sala de aula, a participação nas atividades jamais é compulsória ou forçada:

Assim, não existe participação dada, imposta, prévia ou suficiente [4], mas sim fruto do exercício da cidadania com reais e iguais oportunidades em todos os níveis e se espera a participação consciente que implica na compreensão do processo que estão vivenciando. [5]

QUADRO 1

PEDAGOGIA EM EAD

\begin{tabular}{|l|l|l|l|}
\hline \multirow{2}{*}{} & \multicolumn{3}{|l|}{ Geração da Pedagogia em EAD } \\
\cline { 2 - 4 } & $\begin{array}{l}\text { Behaviorismo } \\
\text { Cognitivo }\end{array}$ & Construtivismo & Conectivismo \\
\hline Tecnologia & $\begin{array}{l}\text { Mídias de Massa, } \\
\text { impressos, TV, } \\
\text { rádio ... } \\
\text { Um-para-um }\end{array}$ & $\begin{array}{l}\text { WEB conference } \\
\text { Muitos-para- } \\
\text { muitos }\end{array}$ & $\begin{array}{l}\text { WEB 2.0 } \\
\text { redes sociais, } \\
\text { agregação }\end{array}$ \\
\hline Atividades & Ler e assistir & $\begin{array}{l}\text { Discutir, criar e } \\
\text { construir }\end{array}$ & $\begin{array}{l}\text { Conectar, ex- } \\
\text { plorar, avaliar e } \\
\text { criar }\end{array}$ \\
\hline $\begin{array}{l}\text { Papel do } \\
\text { Professor }\end{array}$ & $\begin{array}{l}\text { Criador de } \\
\text { Conteúdo, sábio }\end{array}$ & $\begin{array}{l}\text { Lider e guia da } \\
\text { discussão }\end{array}$ & $\begin{array}{l}\text { Coadjuvante, } \\
\text { crítico }\end{array}$ \\
\hline
\end{tabular}

Santos [6] aborda sobre as novas formas de opressão que passam a ser desvendadas ao assumirmos a nova democracia:

A nova teoria democrática deverá proceder à repolitização global da prática social e o campo político imenso que dai resultará permitirá desocultar formas novas de opressão e de dominação, ao mesmo tempo que criará novas oportunidades para o exercício de novas formas de democracia e de cidadania. [6]

Ao referir-se à educação (nos dias de hoje, ainda predominante em muitos educandários), Freire [7] nos remete a:

concepção bancária que estamos criticando, para a qual a educação é o ato de depositar, de transferir, de transmitir valores e conhecimentos, não se verifica nem pode verificar-se esta superação. Pelo contrário, refletindo a sociedade opressora, sendo dimensão da cultura do silêncio, a educação bancária mantém e estimula a contradição.

a) $[\ldots]$

i) o educador identifica a autoridade do saber com sua autoridade funcional, que opõe antagonicamente à liberdade dos educandos; estes devem adaptar-se às determinações daquele;

j) o educador, finalmente, é o sujeito do processo; os educandos, meros objetos.

\section{OS AMBIENTES VIRTUAIS}

Com o fortalecimento da internet, proporcionado pelo menor custo das novas tecnologias, sedimentou-se a construção dos ambientes virtuais, que mais tarde chamaríamos de Virtual Learning Environment (VLE), Ambiente Virtual de Aprendizado ou ainda Ambientes Virtuais de Ensino e Aprendizagem (AVEAs).
Os primeiros projetos de construção de ambientes virtuais de aprendizagem destinados à educação iniciaramse em meados da década de 1990, depois de uma significativa mudança na internet, devido a dois acontecimentos: a criação do primeiro navegador para a web; a internet deixa de ser uma rede academica, incorporando atividades de empresas. Antes da web, era possível usar a rede por meio de telas textuais, sendo que um grande avanço ocorreu com a tecnologia de janelas gráficas, cuja vantagem da janela gráfica foi permitir a representação da informação na forma de imagens e trazer uma linguagem icônica nas telas dos computadores. [8]

mbora sejam os alunos muito criativos, é preciso estimular, trazer exemplos que se identifiquem como o cotidiano e assim proporcionar um aprendizado efetivo:

A simples navegação num universo de informação em rede não se traduz numa aprendizagem efetiva, sendo necessário da parte do aprendente um envolvimento nas atividades e tarefas em curso; por outras palavras, supõe uma atitude de abertura à participação ativa. [9]

Há que recordarmos também alguns conceitos, como o de e-learning e Ensino a Distância (EAD).

Um conceito-chave que muitas vezes fica esquecido, é que e-learning trata da aprendizagem e não da tecnologia, sendo que alguns e-learning são apenas uma tecnologia em busca de uma utilização e sem qualquer valor educativo real. [10]

Salmon [11] acrescenta afirmando que e-learning "tem quase nada a ver com computadores e tudo a ver com tempo, motivação, conhecimento [...], assim como com o bom e adequado ensino".

Em suma, "e-learning é basicamente uso da tecnologia eletrônica para dar suporte, aperfeiçoar e proporcionar aprendizagem, é simplesmente mais uma ferramenta a disposição do ensino" [10].

O uso de alguns dos artefatos aqui mencionados, ocorreram circunstancialmente, um deles, por exemplo, a lousa digital, ocorreu em uma fase em que por uma limitação legal, nossa organização não disponha de marcadores (canetas) para escrever no quadro branco (lousa). A adoção de repositório de dados e bases de conhecimento (seja Moodle ou Word Press - WP) ocorreu pela necessidade de complementar o acervo da biblioteca, a qual em alguns campus, ainda em implantação. A adoção de jogos, do uso de sistemas computacionais voltados para informações gerenciais, programas emuladores via WEB, se deve ao conhecimento tácito e explícito de alguns professores no seu uso e muitas vezes no seu desenvolvimento.

\section{O USO DAS “FERRAMENTAS E ARTEFATOS”}

\section{A. Moodle como repositório}

Temos observado que o uso de questionários e avaliações via Moodle não tem sido um grande sucesso, talvez por inexperiência dos professores. Um dos usos mais comuns tem sido a recepção de arquivos com os trabalhos e tarefas. Nesse caso, além de vantagens óbvias como poupar árvores, um dos fatores muito importantes para os professores é que registra o horário data, número de acessos, entre outros.

A versão utilizada em nossa instituição não apresenta um interface direto com o sistema acadêmico para inter- 
cambio de conceitos $^{1}$ e formação de turmas, o que proporcionaria uma facilidade adicional. Uma coisa boa é poder enviar mensagens a todos os alunos através do Moodle, o que é fácil e eficaz (Figura 1).

\section{B. Lousa Digital}

Como resultados imediatos, a lousa digital supre uma das lacunas muito fortes hoje no ensino médio, que se refere à falta de hábito dos alunos em fazer anotações. Dessa forma, além dos recursos de imagem e outros didáticos, provê de forma substancial uma base de conhecimento registrada para acesso do aluno, especialmente, no caso das avaliações. É muito fácil complementar as anotações, gerar arquivos em formato PDF e disponibilizar no Moodle.

Seu uso permite, também, selecionar telas, imagens, desenhos, enunciados de exercícios pré-definidos e transportá-los diretamente à área de trabalho para ser manipulado, alterado e resolvido.

Links diretos podem ser fixados para sites como YouTube, por exemplo, outras páginas, apresentações tipo Power Point. O uso de diversas cores e espessuras de traço permite enfatizar as informações e a facilidade em retroceder e avançar páginas (o que não pode ser feito no quadro negro), caracterizando, assim, mais uma das facilidades muito interessantes, pois o professor pode fazer o link dos temas com muito mais das facilidades, despertando, assim, o interesse do aluno (Figura 2).

\section{Uso do Word Press}

Uma das formas de fazer o repositório de conhecimento e de forma que permita comentários é o WP (Figura 3). Diferentemente do Moodle, sua visualização e facilidade para deixar mensagens e textos é melhor e mais prática. Referencias a temas, uma e outra página de texto, livro, links para artigos e comentários são mais fáceis de utilizar e instigam a curiosidade do aluno. A possibilidade de download e upload também é algo a ser considerado, para estabelecer as prioridades de interesse nos temas abordados.

Como requisito básico, a recomendação é que o site tenha um nome de fácil memorização, para que os alunos encontrem facilmente (em nosso caso tabajara.tv).

\section{Uso do Facebook}

Para poder se comunicar de modo efetivo, o professor necessita por vezes "ir onde o aluno está" - deve participar com os devidos cuidados. Nada mais atual que as redes sociais e, nesse caso, o Facebook tem demonstrado excelentes resultados seja para divulgar o conteúdo de uma aula (link para arquivos gerados pela lousa digital, links para o repositório do WP) ou mesmo recordando de alguma tarefa a ser postada no Moodle (Figura 4). Nesse quesito, o Facebook supera ao Tweeter por possuir mensagens maiores e facilidades para outros tipos de arquivos.

Pode, também, o professor (ressalvados os devidos cuidados), nos fóruns adequados, perceber a real dificuldade de alguns alunos, pois é comum algum desabafo relativo aos desafios encontrados nas unidades curriculares. O outro aspecto relevante é que alguns alunos que apresentam comportamento introvertido em sala de aula, se sentem mais à vontade para expressar-se

\footnotetext{
Utilizamos conceitos ao invés de notas. (EPSI - Excelente, Proficiente, Suficiente e Insuficiente)
}

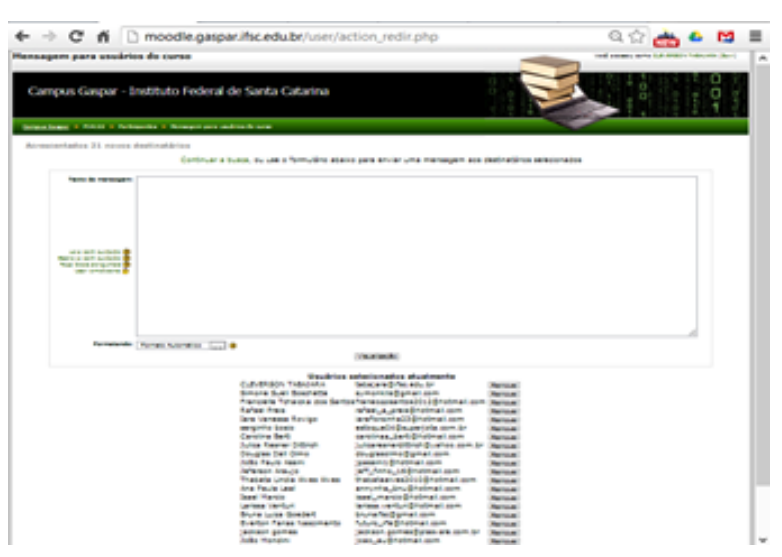

Figura 1. Uso do moodle para enviar mensagens aos participantes

Fonte: Acervo dos autores

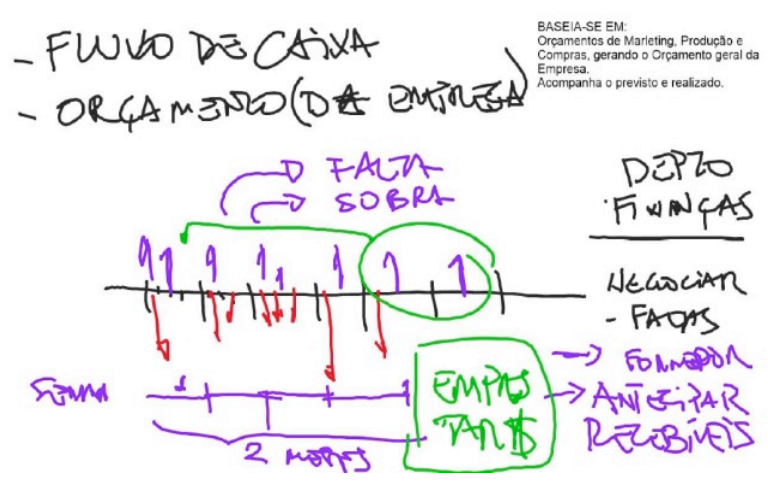

Figura 2. Lousa digital como apontamento para o aluno (aula fluxo de caixa). Fonte: acervo dos autores.

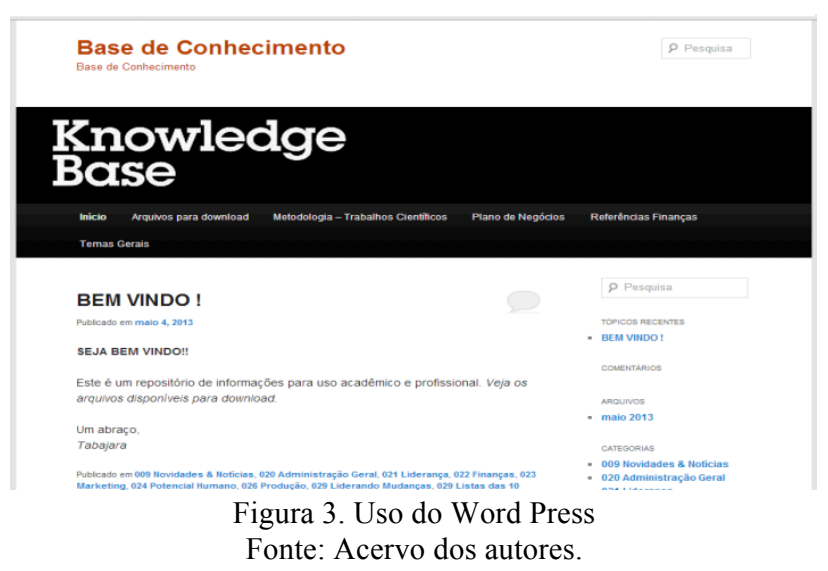

através da telinha e isto facilita ao professor perceber quais os temas de interesse de cada aluno.

Não fizemos qualquer preparação dos alunos, nem recomendações, apenas utilizamos um grupo criado no Facebook; é interessante anotar aqui um estudo publicado no International Journal of Emerging Tecnology in Leaning (IJET, vol 8, n. 3, 2013) desenvolvido por Troussas et all [12], com o uso educacional do Facebook, onde foi implementada uma aplicação dirigida a gregos que querem aprender a estrutura gramatical em filipino e viceversa. Nesse trabalho, proporcionaram a adaptação do usuário e a individualização, visto ser um grupo heterogêneo, o que não é característica dos nossos alunos. 


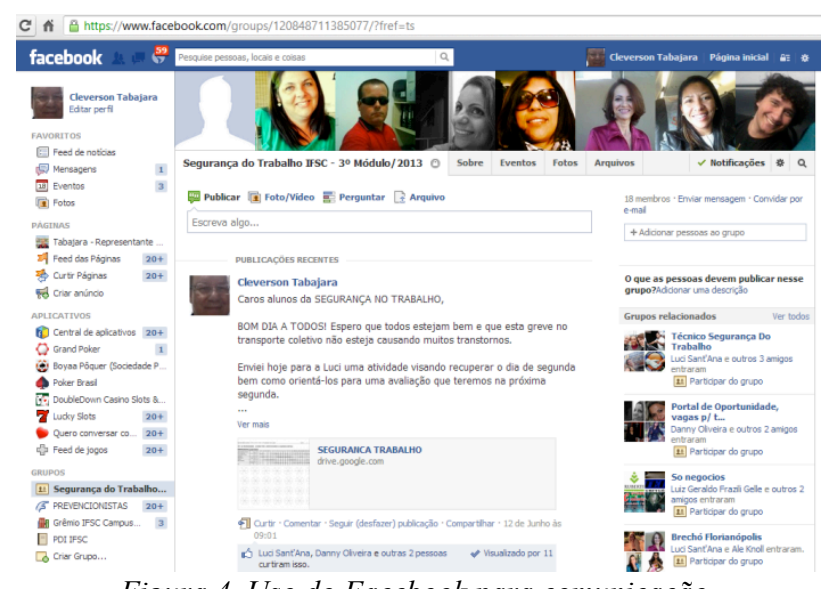

Figura 4. Uso do Facebook para comunicação. Fonte: Acervo dos autores.

Um aspecto que devemos mencionar, mesmo utilizando apenas para efeitos de comunicação informal com os alunos, se refere à privacidade e monitoramento. No $F a$ cebook, no caso de um grupo fechado, a privacidade se torna no mesmo nível do Moodle, no entanto, perdendo em capacidade de monitoramento que o Moodle provê (hora de acesso, etc).

\section{E. Sistemas ERP - SIG em demonstração.}

Algo que atrai os alunos nos cursos técnicos é a possibilidade de utilizar softwares ligados à sua área de atuação. Em um dos laboratórios de informática, instalamos, com o auxílio do pessoal de Tecnologia do Campus, alguns softwares que foram cedidos pelos fabricantes. Esses softwares ficam em um repositório base e antes de cada aula são instalados em uma área que vai ser compartilhada e acessada pelos alunos.

É muito interessante observar as reações dos alunos aos sistemas, onde mais de 30 usuários estão acessando a mesma página do programa. Além das funcionalidades observadas nos programas como as funções de cadastro, baixa, relatórios, os alunos podem comprovar as especificações não funcionais, como tempo de resposta e usuários simultâneos. Outra coisa que acontece, é que os softwares, devido à carga excessiva e condições inusitadas de utilização, apresentam por vezes lentidão e travamentos e isso é considerado bom, pois quando ocorre na vida real o aluno está pronto para atuar e contornar essa dificuldade.

Exercitar o cadastramento de Grupos/Famílias de produtos, cadastro de produtos, fornecedores, fazer as compras, a requisição dos produtos, faz com que os conceitos de sala de aula, como FIFO, LIFO, Preço Médio, Giro de Produtos, sejam vivenciados como na empresa (Figura 5). O controle financeiro, registro, baixas, pagamentos diretos, pela tesouraria, os controles de inadimplência são utilizados. Outras funções como recrutamento, seleção, banco de candidatos são exemplificados e especialmente a interligação entre os módulos, evidenciando ao aluno que a entrada de um produto tem seus efeitos financeiros, legais, físicos, etc.

Uma recomendação que podemos fazer a todos os produtores de software que podem encontrar nas escolas técnicas excelentes formas de testar seus aplicativos, divulga-los e criar uma cultura de utilização de seus produtos.

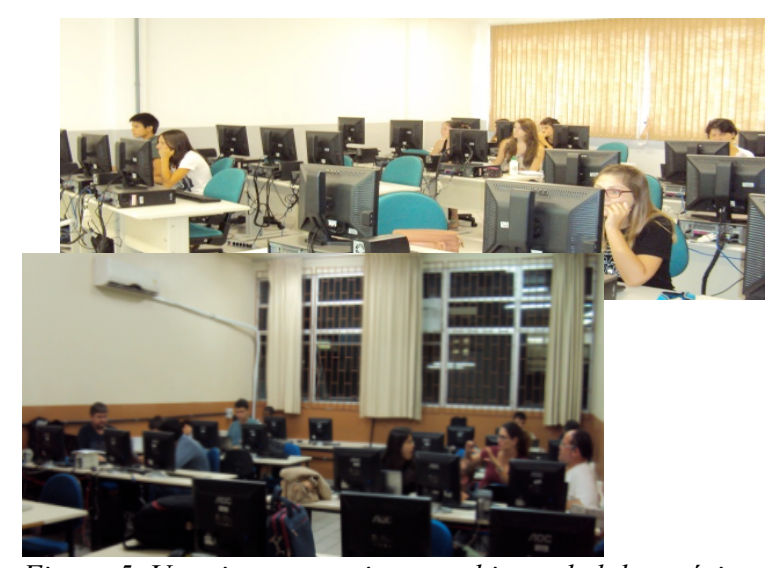

Figura 5. Uso sistemas reais em ambiente de laboratório. Fonte: Acervo dos autores.

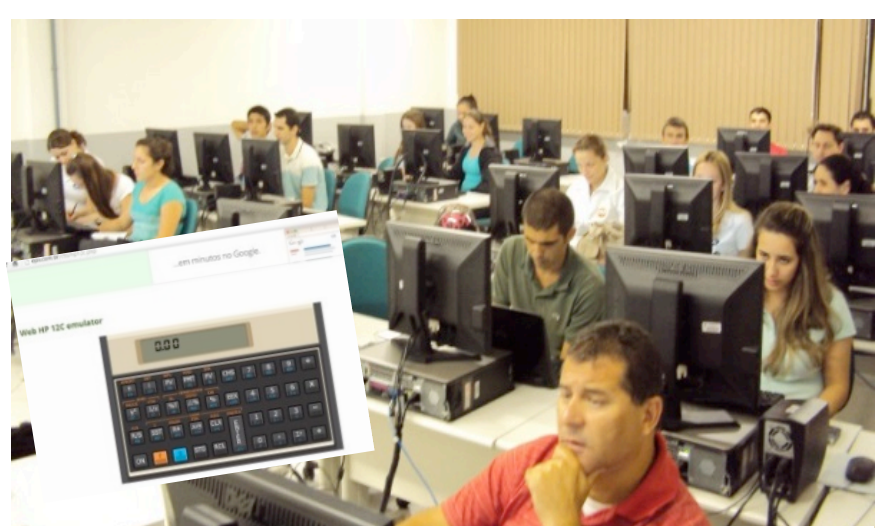

Figura 6. Uso de emuladores nos laboratórios de informática, como neste caso o uso da HP12C.

Fonte: Acervo dos autores.

\section{F. Uso de programas simuladores via WEB.}

Uma das coisas boas é poder utilizar programas livres e que são operados diretamente pela internet e sem a necessidade de instalação e nem mesmo configuração.

Em algumas disciplinas, como Finanças, o uso de emuladores da calculadora HP12C tem se tornado um importante aliado para desenvolver o raciocínio da matemática financeira e a solução de problemas (Figura 6).

Após uma rápida introdução teórica sobre o tema (por exemplo taxas de juros, juros compostos, etc.) os alunos partem para exemplos encontrados diretamente na internet, como ofertas de lojas onde o slogan se refere "a sem desconto e sem acréscimo", mas onde há um desconto para pagamento à vista. Logo, a percepção dos alunos modifica, entendendo que há um custo do dinheiro e este está embutido nos preços. Fica saliente a diferença entre aplicar na poupança e fazer um financiamento com juros mensais equivalentes a um ano na poupança.

Essa é uma das relevantes contribuições para o futuro dos alunos como cidadãos, onde percebem não apenas as vantagens financeiras de uma poupança ou de uma compra à vista, mas que todas as teorias de marketing, finanças e produção convergem para o paradigma dominante funcionalista [13], onde produção e mercado são os "deuses". Despertam interesse por coisas simples da cidadania e do mundo capitalista, como a poupança, a propaganda enganosa, o valor do dinheiro e o trabalho assalariado. 


\section{G. Uso de jogos, teatro, filmes e outros recursos}

Tendo em vista que em nosso grupo de pesquisas há projetos específicos voltados para este tópico, dirigidos por outros professores, traremos aqui apresentar apenas a nossa percepção direta acerca dos resultados produzidos em nossos alunos.

Ainda que, através das lentes do cinema ou através de jogos simulados, o que observamos é que, bem explorados, esses recursos produzem analogias marcantes e revelam uma boa ligação entre o cotidiano e as teorias acadêmicas.

Gomes e Friedrich [14] salientam que o jogo no ambiente educacional é sempre o meio e não o fim e nem sempre foi visto como didático, pois como a ideia de jogo se encontra associada ao prazer, assume pouca importância para a formação do estudante. Sua utilização como meio educativo demorou a ser aceita.

Nas oportunidades em que estabelecemos tarefas e atividades que simulavam as situações reais, o interesse pelos alunos foi elevado, não só em função do lúdico, mas pelas analogias com o cotidiano. Percebemos que especialmente, as habilidades de comunicação se tornam mais efetivas.

Os filmes requerem uma seleção delicada, uma preparação, e para sua apresentação noturna, requer que sejam mais pontuais e curtos, visando minimizar os efeitos que o cansaço de um dia de trabalho podem oferecer à sala de aula.

Já o teatro nos apresenta a "metamorfose" do aluno; para Gonzaga e Braga [15], o teatro na escola pode ser visto como uma preparação para superar os futuros desafios; diferente da televisão ou cinema, o ator percebe no espectador sua reação, o que influi em sua atuação e faz aflorar as emoções; a emoção e intuição permanecem em alta e também começam a participar de suas vida como algo normal.

Algumas ações realizadas, como teatro e jogos, são ilustradas na Figura 7.

\section{ACHADOS E OBSERVAÇÕES}

A primeira observação é também óbvia: a tecnologia está presente em tudo, desde a atenção do aluno até as ferramentas para a sala de aula. É inútil resistir a essa "onda de modernidade" e a forma imediata de melhorar os resultados é sua adoção imediata. Seja qual for a ferramenta ou o domínio que tenha o professor sobre ela, adotá-la é melhor que não fazer nada ou tentar proibir seja o uso do notebook, do celular, tablete, etc. Nem trancando a porta da sala isto vai resolver!

Spolin [15] afirma que, ao aumentarmos a experienciação em sala de aula, estamos evocando o potencial de cada um e nem sempre exploramos o intuitivo, dando preferência aos níveis intelectual e físico. Consideramos, ainda, a intuição como algo privilegiado e que não é para todos. Percebemos que complexos conceitos de matemática financeira são absorvidos, quando o aluno não tem de se preocupar com fórmulas matemáticas e está voltado para entender (intuitivamente) a situação em que se encontra.

Tecnologias recentes por vezes não encontram eco entre alguns professores, o que pode significar um ambiente de aprendizado que requer mais esforço e dissabores; já com relação ao modelo pedagógico, o professor deve se

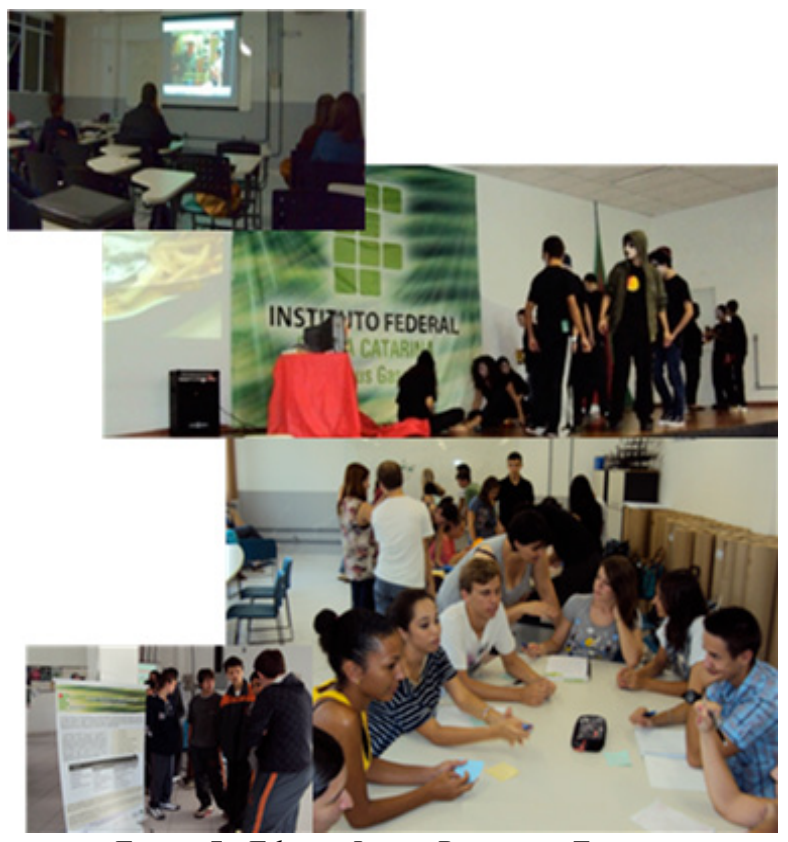

Figura 7. Filmes, Jogos, Projetos e Teatros.

Fonte: Acervo dos autores.

comportar como se estivesse manuseando malabares, buscando manter todos em movimento e sincronizados.

As experimentações realizadas tem gerado nos alunos um clima que afasta o conceito de organização opressora (as escolas são comparadas pelos alunos, a penitenciárias e hospícios), onde para manter o público é preciso trancar as portas. Mais livres no teatro e nos jogos, geram analogias, visões críticas, estimulam a intuição, afloram emoções e subsidiam as funções da inteligência. Novas ferramentas, como as redes sociais, produzem efeitos de comunicação muito superiores aos antigos métodos (mesmo o e-mail) e proporcionam ao professor um conhecimento melhor do aluno no que se refere à sua forma de comunicar e compreender o mundo em que vive e de sonhar. Temos em Freire [17]:

É que lido com gente. Lido, por isso mesmo, independentemente do discurso ideológico negador dos sonhos e das utopias, com os sonhos, as esperanças tímidas, às vezes, mas às vezes, fortes, dos educandos. Se não posso, de um lado estimular os sonhos impossiveis, não devo, de outro, negar a quem sonha o direito de sonhar. Lido com gente e não com coisas.

Este trabalho desenvolvido em 2012-2013 é um começo e pretendemos fazer nova análise em 3 anos, quando seu resultado será ainda mais evidenciado.

\section{REFERÊNCIAS}

[1] TAPSCOTT, Don. WILliAMS, Anthony D. WIKINOMICS How mass collaboration changes everythings. London-GB. Grove Atlantic Ltd, 2008.

[2] DRON, Jon, ANDERSON, Terry. TRÊS GERAÇÕES DE PEDAGOGIA DE EDUCAÇÃO A DISTÂNCIA, Tradução: João Mattar, Athabasca University, Fundação Cecierj, Athabasca University- Canadá,2011, Rio de Janeiro - Novembro 2012.

[3] RAMOS, Alberto Guerreiro. A nova ciência das organizações: uma reconceituação da riqueza das nações . Editora da Fundação Getúlio Vargas,Rio, 1989, p. 194.

[4] DEMO, Pedro. Participação é conquista. São Paulo: Ed. Cortez, 2001, p. 41. 
[5] TENÓRIO, F.G.; ROZENBERG, J. E. Gestão pública e cidadania: metodologia participativas em ação. v. 7. Rio de Janeiro: FGV, 1997.

[6] SANTOS, Boaventura Sousa, Pela mão de Alice: o social e o político na pós-modernidade. São Paulo: Cortez, 1995

[7] FREIRE, Paulo. Pedagogia do oprimido, $17^{\mathrm{a}}$. ed. Rio de Janeiro, Paz e Terra,1987, p. 179.

[8] FRANCO, Marcelo Araújo; CORDEIRO, Luciana Meneghel e CASTILLO, Renata A. Fonseca del. O ambiente virtual de aprendizagem e sua incorporação na Unicamp. Educ. Pesqui. [online]. 2003, vol.29, n.2, pp. 341-353. ISSN 1517-9702, p. 3.

[9] DIAS, P. Desenvolvimento de objectos de aprendizagem para plataformas colaborativas. Actas do VII Congresso Iberoamericano de Informática Educativa. Monterrey, México, 2005, p. 182.

[10] HALL, Chris; BERG, Nicola; ADAMSON, kemi. WHAT IS ELEARNING?, A guide to e-learning, Out-2007, p. 2.

[11] SALMON, Gilly. What is e-moderating, Stylus Publishing, Sterling VA, USA, 2000

[12] TROUSSAS, Christos, VIRVOU, Maria, CARO, Jaime, ESPINOSA ,Kurt Junshean. Language Learning Assisted by Group Profiling in Social Networks, iJET-International Journal of Emerging Technologies in Learning - Vol 8, No 3, 2013

[13] BURRELL, G.; MORGAN, G. Sociological paradigms and organisational analysis. Vermont: Ashgate Publishing, 1979.

[14] GOMES, R.R. e FRIEDRICH, M.A.. Contribuições dos jogos didáticos na aprendizagem de conteúdos de Ciências e Biologia. Rio de Janeiro, Anais, EREBIO, 2001.
[15] GONZAGA, Graciele Batista; BRAGA, Lina Paula de Fátima; Professor colaborador: ANDRADE, Fabrício. Teatro na Escola: uma possibilidade para superar os desafios do futuro: Revista Digital Art- Ano IV - Número 05 - Abril de 2006 www.revista.art.br/site-numero-05/trabalhos/11.htm. Acesso em 10 jul 2013.

[16] SPOLIN, Viola. Improvisação para o Teatro. Tradução e Revisão: KOUDELA,Ingrid Dormien; AMOS, Eduardo José de Almeida:Produção: NEVES, Ricardo W. ABRANCHES, Raquel Fernandes.In. Perspectiva, $2008-5^{\circ}$ edição- (Coleção Estudos dirigida por J. Guinsburg).

[17] FREIRE, Paulo. Pedagogia da Autonomia. In. Paz e Terra, 2009$39^{\circ}$ Edição, São Paulo, p. 144.

\section{AUTORES}

VIANNA, Cleverson Tabajara, Instituto Federal de Educação, Ciência e Tecnologia de Santa Catarina (tabajara@ifsc.edu.br).

TENFEN, Glaucia Marian, Instituto Federal de Educação, Ciência e Tecnologia de Santa Catarina (glaucia.tenfen@ifsc.edu.br).

CÂNDIDO, Antônio Pereira, Instituto Federal de Educação, Ciência e Tecnologia de Santa Catarina (apec@ifsc.edu.br).

Submitted 19 March 2014. Published as re-submitted by the authors 05 April 2014. 